OPEN ACCESS

Edited by:

Xiaoshou Liu,

Ocean University of China, China

Reviewed by:

Qing Wang,

Yantai Institute of Coastal Zone

Research, Chinese Academy

of Sciences (CAS), China

Jiji Li,

Zhejiang Ocean University, China

*Correspondence:

Wei Huang

willhuang@sio.org.cn

Youji Wang

youjiwang2@gmail.com

${ }^{\dagger}$ These authors have contributed equally to this work

Specialty section:

This article was submitted to Marine Pollution,

a section of the journal

Frontiers in Marine Science

Received: 07 August 2021

Accepted: 16 August 2021

Published: 01 September 2021

Citation:

Shang $Y$, Wang $X$, Chang $X$, Sokolova IM, Wei S, Liu W, Fang JKH, Hu M, Huang W and Wang Y (2021)

The Effect of Microplastics on

the Bioenergetics of the Mussel Mytilus coruscus Assessed by Cellular

Energy Allocation Approach.

Front. Mar. Sci. 8:754789.

doi: 10.3389/fmars.2021.754789

\section{The Effect of Microplastics on the Bioenergetics of the Mussel Mytilus coruscus Assessed by Cellular Energy Allocation Approach}

\author{
Yueyong Shang ${ }^{1,77}$, Xinghuo Wang ${ }^{1,7+}$, Xueqing Chang ${ }^{1,7}$, Inna M. Sokolova ${ }^{3,4}$, \\ Shuaishuai Wei ${ }^{1,7}$, Wei Liu ${ }^{5}$, James K. H. Fang ${ }^{6}$, Menghong Hu'1,7, Wei Huang ${ }^{2,8 *}$ and \\ Youji Wang ${ }^{1,2,7 *}$
}

\begin{abstract}
1 International Research Center for Marine Biosciences, Ministry of Science and Technology, Shanghai Ocean University, Shanghai, China, ${ }^{2}$ State Key Laboratory of Satellite Ocean Environment Dynamics, Second Institute of Oceanography, Ministry of Natural Resources, Hangzhou, China, ${ }^{3}$ Department of Marine Biology, Institute for Biological Sciences, University of Rostock, Rostock, Germany, ${ }^{4}$ Department of Maritime Systems, Interdisciplinary Faculty, University of Rostock, Rostock, Germany, ${ }^{5}$ Department F.-A. Forel for Environmental and Aquatic Sciences, Environmental Biogeochemistry and Ecotoxicology, Faculty of Sciences, Earth and Environment Sciences, University of Geneva, Geneva, Switzerland, ${ }^{6}$ Department of Applied Biology and Chemical Technology, The Hong Kong Polytechnic University, Kowloon, Hong Kong, ${ }^{7}$ Key Laboratory of Exploration and Utilization of Aquatic Genetic Resources, Ministry of Education, Shanghai Ocean University, Shanghai, China, ${ }^{8}$ Key Laboratory of Marine Ecosystem Dynamics, Second Institute of Oceanography, Ministry of Natural Resources, Hangzhou, China
\end{abstract}

Marine microplastics pollution is a major environmental concern in marine ecosystems worldwide, yet the biological impacts of microplastics on the coastal biota are not yet fully understood. We investigated the impact of suspended microplastics on the energy budget of the mussels Mytilus coruscus using the Cellular Energy Allocation (CEA) approach. The mussels were exposed to control conditions (no microplastics) or to one of the three concentrations of $2 \mu \mathrm{m}$ polystyrene microspheres $\left(10,10^{4}\right.$, and $10^{6}$ particles/L) for 14 days, followed by 7 days of recovery. Exposure to high concentrations of microplastics $\left(10^{4}\right.$ or $10^{6}$ particles/L) increased cellular energy demand (measured as the activity of the mitochondrial electron transport system, ETS) and depleted cellular energy stores (carbohydrates, lipids, and proteins) in the mussels whereas exposure to 10 particles/L had no effect. Carbohydrate levels decreased already after 7 days of microplastics exposure and were restored after 7 days of recovery. In contrast, the tissue levels of lipids and proteins declined more slowly (after 14 days of exposure) and did not fully recover after 7 days following the removal of microplastics. Therefore, the total energy content and the CEA declined after 7-14 days of exposure to high microplastics concentrations, and remained suppressed during 7 days of subsequent recovery. These findings demonstrate a negative impact of microplastics on energy metabolism at the cellular level that cannot be restored during a short time recovery. Given a close link of CEA with the organismal energy balance, suppression of CEA by microplastics exposure suggests that bioenergetics disturbances might lead to decreases in growth and productivity of mussels' populations in environments with heavy microplastics loads. 


\section{INTRODUCTION}

An exponential increase in production and use of plastic materials leads to a rise in the amount of plastic waste in aquatic habitats worldwide (Andrady and Neal, 2009; Wang C. et al., 2020). Ocean is a major sink for plastic waste with estimated $>150$ million tons of plastics present in marine ecosystems (MacArthur, 2017). Over time, the plastic waste breaks down into microplastics $(0.1 \mu \mathrm{m}-5 \mathrm{~mm}$ in diameter $)$ and nanoplastics (diameter $<0.1 \mu \mathrm{m}$ ) through microbial degradation, prolonged UV exposure or physical abrasion (Weis et al., 2015). Microplastics have been globally detected in aquatic environments, including beaches, sediments and water column (Zhao et al., 2018; Teng et al., 2019; Li et al., 2020; Wang C. et al., 2020) and are considered ubiquitous emergent contaminants in marine ecosystems (Rochman et al., 2019). One of the major concerns related to the environmental impacts of microplastics is their interference with organisms' feeding (Botterell et al., 2019). Due to their small size, microplastics are easily ingestible by marine organisms and can accumulate in their digestive tract and other tissues potentially interfering with the digestion and nutrient uptake (Wright et al., 2013a,b). Furthermore, accumulated microplastics might induce indirect energetic costs due to the toxicity and tissue damage (Sokolova, 2021), and can also be transferred and enriched through the food chain, thus posing both ecological and human health threats (Brandts et al., 2018; Yu et al., 2018; Larue et al., 2021). The ingestion of microplastics by marine biota has been extensively documented in the laboratory experiments and in the field (Khan and Prezant, 2018; Pinheiro et al., 2020; Xu et al., 2020; Müller, 2021), but its implications for nutrition and energy metabolism remain insufficiently well-studied in marine organisms, including suspension feeders (such as bivalves) that are considered one of the most susceptible trophic guilds for microplastics (Wright et al., 2013a,b).

An emerging paradigm in the environmental risk assessment of microplastics considers that ingestion of microplastics might alter the food consumption and energy allocation in marine species (Galloway and Lewis, 2016). Microplastic might prevent the adequate intake of food and incur high energetic cost due to impaired internal homeostasis and upregulation of energetically costly protective mechanisms, such as immune system and cellular stress response (Détrée and GallardoEscárate, 2018). This implies that organisms must draw from their energy reserves to satisfy the metabolic demand and/or reallocate energy from fitness-related processes, such as growth or reproduction toward maintenance to compensate for energy deficiency caused by microplastics exposure (Wright et al., 2013a; Gardon et al., 2018). Earlier studies in aquatic organisms (including bivalves, polychaetes, and crustaceans) exposed to microplastics reported suppression of the feeding rates, decrease in growth, and depletion of energy stores (Wright et al., 2013a; Watts et al., 2015; Yin et al., 2018; Pedersen et al., 2020). These changes indicate elevated energy costs of dealing with stress in suboptimal environments and imply negative shifts in the energy budget of the organism limiting the amount of energy allocated into growth under by microplastic exposures. Energy budget of an organism can be assessed at the organismal level by measuring the amount of assimilated energy and energy lost to respiration and excretion to determine the energetic Scope for Growth (SFG) (Widdows and Johnson, 1988) or biochemically by assessing the amount of energy reserves and energy consumption at the cellular level using the Cellular Energy Allocation (CEA) approach (De Coen and Janssen, 1997, 2003; Verslycke et al., 2003, 2004a; Smolders et al., 2004). The CEA approach provides an ecologically relevant tool to assess the energy budget of an organism linking changes at the cellular level with higher levels of biological organization (De Coen and Janssen, 1997; Smolders et al., 2004) and is commonly used in ecotoxicological assessments as an early indicator of pollutant-induced stress (De Coen and Janssen, 2003; Smolders et al., 2004; Van Dievel et al., 2019; Noor et al., 2021; Wu et al., 2021). Given the direct impact of microplastics on feeding behavior and maintenance costs of animals (Wright et al., 2013a; Watts et al., 2015; Galloway and Lewis, 2016; Yin et al., 2018; Pedersen et al., 2020), determination of CEA could provide important insights into the physiological and ecological consequences of exposures to these important emerging pollutants in marine organisms.

The aim of our present study was to determine the impacts of microplastics exposures on bioenergetics of the mussels (M. coruscus) using the CEA approach. Mussels are excellent bioindicators for environmental impacts of microplastics due to their wide distributing, key ecological functions as ecosystem engineers, and significant roles in marine food webs and human food security (Li et al., 2019). As filter-feedings, marine mussels can take up and accumulate microplastics (Hamm and Lenz, 2021). The energy metabolism of mussels is sensitive to environmental stressors including pollutants so that shifts in the energy budget provide a sensitive measure of stress in these organisms (Sokolova et al., 2012). Earlier studies reported that microplastics can increase the respiration rate (Green, 2016) and reduce the feeding rate of the mussels (Pedersen et al., 2020), which can have direct impact on their energy budget. Therefore, we hypothesized that microplastics could cause disturbances in the energy status of the mussel resulting in higher energy demand for basal maintenance and decreased energy reserves and reflected in low CEA. We also hypothesized that the severity of the negative bioenergetic effects of microplastics and the ability of mussels for subsequent recovery will depend on the concentration of microplastics. To test these hypotheses, we exposed the mussels $M$. coruscus) to different concentrations of suspended polystyrene microplastics $\left(0,10,10^{4}\right.$, and $10^{6}$ particles/L) for 14 days followed by 7 days of recovery, and measured CEA indicators including the available energy $\left(\mathrm{E}_{\mathrm{a}}\right)$ by determining the protein, lipid, and carbohydrate content of the tissues, the energy consumption $\left(\mathrm{E}_{\mathrm{c}}\right)$ assessed as the activity of mitochondrial electron transport system (ETS) activity, and CEA as the ratio of $E_{a}$ and $E_{c}$. This study provides insights into the bioenergetics consequences of microplastic exposure and subsequent recovery in the mussels and helps to close an important gap in our knowledge of physiological and ecological effects of microplastics in marine organisms (Smolders et al., 2004; De Sá et al., 2018). 


\section{MATERIALS AND METHODS}

\section{Preparation and Identification of Microplastics}

The stock solution of $2 \mu \mathrm{m}$ polystyrene microspheres $\left(5.69 \times 10^{9}\right.$ particles $/ \mathrm{mL}, 2.5 \% \mathrm{w} / \mathrm{v}, 10 \mathrm{~mL}$ ) used in the experiment was purchased from BaseLine Chromtech Research Center (Tianjin, China). Fourier transform infrared spectroscopy (Nicolet iN10 MX, Thermo Fisher Scientific) was used to characterize and verify the polystyrene microspheres, and the surface morphology and particle size of polystyrene microspheres were analyzed by scanning electron microscope (SEM, Hitachi JSM-7500F). The physical characterization data of microplastics was reported in our earlier paper (Wang X. et al., 2020).

\section{Sample Collection}

The thick shell mussels (dry weight $1.5 \pm 0.90 \mathrm{~g}$; shell length $7.95 \pm 0.32 \mathrm{~cm}$ ) were collected from Gouqi Island, Zhejiang Province, China ( $\left.30^{\circ} 43^{\prime} 14.268^{\prime \prime} \mathrm{N}, 122^{\circ} 47^{\prime} 0.3696^{\prime \prime} \mathrm{E}\right)$. Only undamaged healthy mussels of similar size were used in the experiment. The shell surface was cleaned from biofouling, and the mussels were placed in laboratory breeding systems equipped with circulating filter devices for 2 weeks (temperature: $25 \pm 0.4^{\circ} \mathrm{C}$; pH: $8.1 \pm 0.05$; salinity: $25 \pm 0.8 \%$; photoperiod: LD 12: $12 \mathrm{~h})$. The mussels were fed with Chlorella vulgaris $\left(5 \times 10^{4}\right.$ cells $\left./ \mathrm{mL}\right)$ twice a day.

\section{Experimental System and Design}

Experimental mussels were randomly divided into four treatment groups and exposed to clean seawater $(0$ particles/L) or to one of the three test concentrations of polystyrene microspheres $(10$, $10^{4}$, and $10^{6}$ particles/L). The concentration of 10 particles/L simulated the microplastic pollution in the Yangtze River estuary offshore (Zhao et al., 2014), and $10^{4}$ and $10^{6}$ particles/L were the concentrations set based on previous toxicology studies of microplastics (Capolupo et al., 2018; Magni et al., 2018). The experiment was conducted in triplicates with a density of 20 mussels per tank (30 L). Coulter counter (Multisizer 3, Beckman, Irvine, CA, United States) was used daily to ensure the stability of the concentration and particle size distribution of microplastics in each treatment group. The mussels were feed with $C$. vulgaris $\left(5 \times 10^{4}\right.$ cells $\left./ \mathrm{mL}\right)$ every day, and half of the seawater $(15 \mathrm{~L})$ was changed in all tanks every day to ensure high water quality. After changing the water, add polystyrene microspheres to maintain concentration to meet the exposure test requirements. After 14 days of microplastics exposures, the seawater in all tanks was completely replaced, and the recovery experiment was carried out for 7 days in the clean seawater without microplastics. The digestive glands of mussels were sampled on day 7,14 of microplastics exposures and on day 21 (corresponding to 7 days of recovery). To minimize the influence of individual differences, the digestive glands of three mussels from the same tank were pooled. The pooled samples were placed in a cryotube, immediately frozen in liquid nitrogen and stored at $-80^{\circ} \mathrm{C}$ until further analyses. The digestive gland was chosen as one of the most metabolically active organs and the main site of energy storage in mussels (Gosling, 1992). For each experimental treatment, three biological replicates (each consisting of the pooled tissues of three mussels) were used.

\section{Energy Reserve and Electron Transfer System Activity Measurement in Digestive Glands}

The chloroform-methanol extraction method was used to determine the lipid content of mussel digestive glands (Van Handel, 1985). The protein content was determined using a commercial kit (Nanjing Jiancheng Bioengineering Institute, China) according to the Coomassie Brilliant Blue colorimetric method (Bradford, 1976). The total carbohydrate content was measured according to the method of De Coen and Janssen using glucose as the standard (De Coen and Janssen, 1997). All absorbances were determined by a microplate reader (Flexstation ${ }^{\circledR}$, Molecular Devices, San Jose, CA, United States). The available energy $\left(E_{a}\right)$ was calculated by summing the energetic values for the different reserves, using an enthalpy of combustion of $17 \mathrm{~kJ} \mathrm{~g}^{-1}$ for glycogen, $39.5 \mathrm{~kJ} \mathrm{~g}^{-1}$ for lipids and $24 \mathrm{~kJ} \mathrm{~g}^{-1}$ for proteins, respectively (Gnaiger, 1983). The ETS activity of mussel digestive glands was measured by the reduction assay of 2-(4-iodophenyl)-3-(4-nitrophenyl)-5phenyl tetrazolium chloride (INT) and was converted into energy equivalents using the oxyenthalpic equivalents of $484 \mathrm{~kJ} / \mathrm{mol}$ $\mathrm{O}_{2}$ for the average mixture of protein, lipid and carbohydrate to represent energy consumption $\left(\mathrm{E}_{\mathrm{c}}\right)$ (Haider et al., 2018). The ratio of $\mathrm{E}_{\mathrm{a}}$ to $\mathrm{E}_{\mathrm{c}}$ was used as a measure for the CEA (Verslycke et al., 2004b).

\section{Statistical Analyses}

SPSS 25 (SPSS Inc., Chicago, IL, United States) software was used for statistical analysis. The data were tested for the homogeneity of variance by Levene's Test, and the normal distribution of the data was tested by Shapiro-Wilk. One-way ANOVA followed by Tukey's HSD test was used to determine the significant differences between different microplastics treatment groups at each time point, and the effects were considered significant if $p<0.05$.

\section{RESULTS}

The energy stored in carbohydrates decreased in the digestive gland of the mussels exposed for 7-14 days to $10^{4}$ or $10^{6}$ particles/L compared with the control group $(p<0.05)$ (Figure 1A). Exposure to 10 particles/L of polystyrene microplastics had no effect on the tissue content of carbohydrates $(p>0.05)$. There was a tendency for concentration-dependent decrease in the carbohydrate content caused by microplastics, but the difference between the mussels exposed to the two highest tested microplastics concentrations was not statistically significant $(p>0.05)$. The tissue levels of carbohydrates returned to the control baseline after 7 days of recovery in all experimental groups (Figure 1A).

The lipid energy content of the digestive gland remained stable at the baseline (control) levels after 7 days of microplastics 

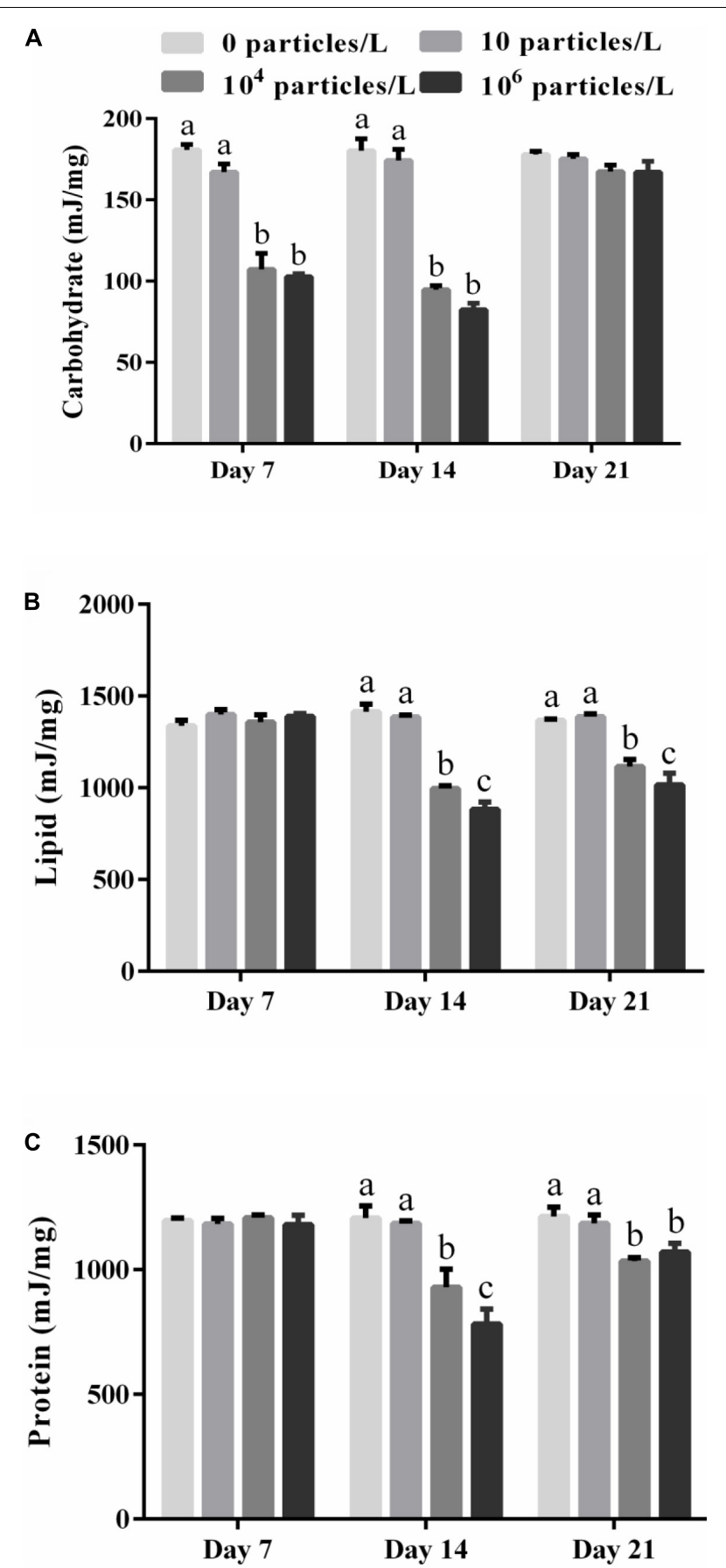

FIGURE 1 | The energy stored in carbohydrates (A), lipids (B), and protein (C) in the digestive gland of $M$. coruscus exposed to different microplastics concentrations $\left(0,10,10^{4}\right.$, and $10^{6}$ particles/L). Different lowercase letters indicate that at the same sampling time point, there are significant differences between different microplastics concentration groups $(p<0.05)$, and no letters indicate that at each sampling time point, there are no significant differences between different microplastic concentration groups $(p>0.05)$.

exposure, but decreased significantly in a concentrationdependent manner after 14 days of exposure (Figure 1B). This decline was significant in the mussels exposed to $10^{4}$ or
$10^{6}$ particles/L $(p<0.05)$. The lipid energy content in the mussels exposed to $10^{4}$ or $10^{6}$ particles/L was not restored after 7 days of recovery compared with the control group $(p<0.05)$ (Figure 1B).

Similar to lipids, the protein energy content of the digestive gland decreased in a concentration-dependent manner after 14 days of exposure to $10^{4}$ or $10^{6}$ particles/L $(p<0.05)$ (Figure 1C). The protein energy content in the mussels exposed to $10^{4}$ or $10^{6}$ particles/L was not restored after 7 days of recovery compared with the control group $(p<0.05)$ (Figure 1C).

The total energy reserve $\left(E_{a}\right)$ of the digestive glands of mussels was not significantly affected by the microplastics after 7 days of exposure but was suppressed in the mussels exposed to $10^{4}$ or $10^{6}$ particles/L after 14 days $(p>0.05)$ (Figure 2A). Recovery for 7 days partially restored the $\mathrm{E}_{\mathrm{a}}$ of the digestive glands of mussels exposed to $10^{4}$ or $10^{6}$ particles/L $(p<0.05)$ (Figure $2 \mathrm{~A}$ ).

The cellular energy consumption $\left(\mathrm{E}_{\mathrm{c}}\right)$ indicative of the energy demand of the mitochondrial ETS increased in the digestive gland of the mussels exposed to $10^{4}$ or $10^{6}$ particles/L after 7 and 14 days of exposure $(p<0.05)$ (Figure $2 B$ ). The lowest tested microplastics concentration (10 particles/L) had no significant effect on $\mathrm{E}_{\mathrm{c}}(p>0.05)$ (Figure 2B). After 7 days of recovery, the $\mathrm{E}_{\mathrm{c}}$ values returned to the control baseline in all experimental groups $(p>0.05)$ (Figure 2B).

The CEA of the mussels was significantly decreased in the digestive gland of the mussels after 7-14 days of exposure and 7 days of recovery in the mussels exposed to $10^{4}$ or $10^{6}$ particles/L $(p<0.05)$ (Figure $2 \mathrm{C}$ ). Exposure to 10 particles/L of polystyrene microplastics and no effect on the CEA of the mussels $(p>0.05)$ (Figure 2C).

\section{DISCUSSION}

Shifts in the cellular energy budget are considered an early warning sign of sublethal toxicity of pollutants in marine organisms with a direct link to organismal fitness (Giesy and Graney, 1989; Smolders et al., 2003). Our present study shows that exposure to high microplastic concentrations $\left(10^{4}\right.$ or $10^{6}$ particles/L) negatively affected the energy balance of the mussels $M$. coruscus with significant carry-over effects after 7 days of recovery. However, the lowest tested microplastics concentration (10 particles/L) had no effect on mussels' bioenergetics. These findings indicate that heavy microplastics pollution presents a health hazard to the mussels due to interference with energy metabolism, yet based on the reported concentrations of microplastics in the water column (ranging from $10^{-4}$ to $10^{2}$ particles/L (Burns and Boxall, 2018; Ma et al., 2020), the environmental risk to the mussels from microplastics exposure is relatively low under the present-day pollution scenarios.

Our present study indicates that elevated energy demand is an important mechanism of the health hazard posed to the mussels by microplastics exposures. This is reflected in an increase in the mitochondrial ETS activity that serves as a marker of cellular energy requirements of mussels (Fanslow et al., 2001; Ivanina et al., 2012) and depletion of tissue 


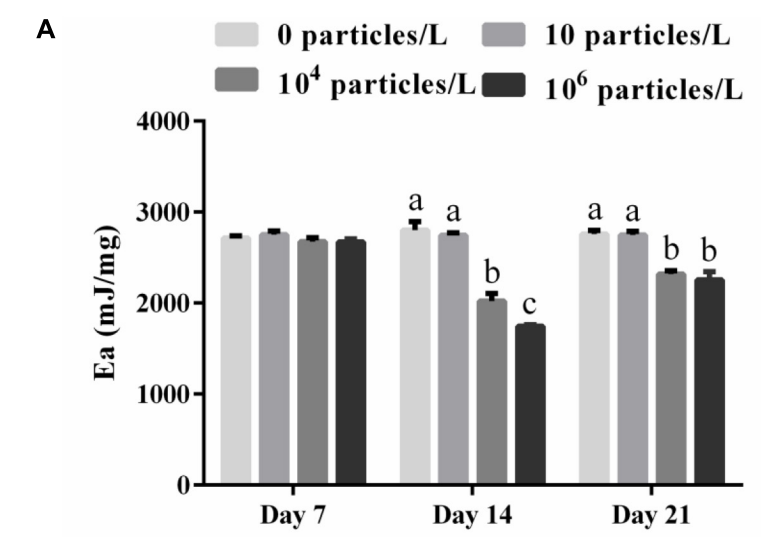

B
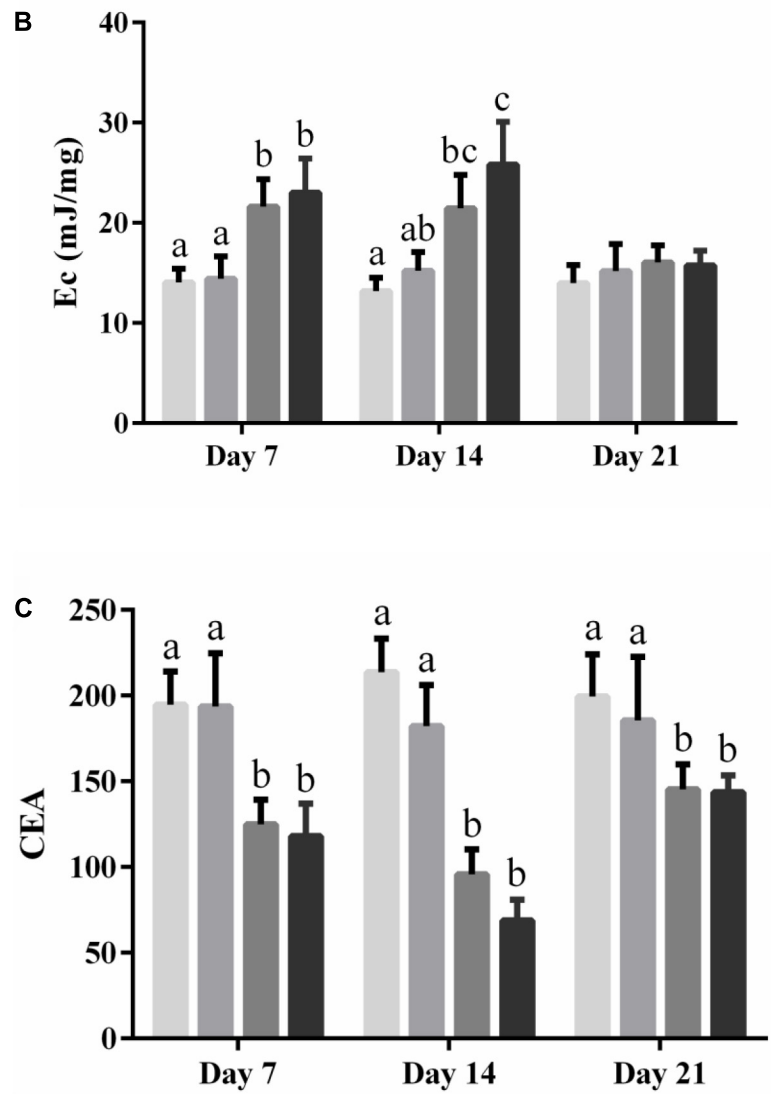

FIGURE 2 | The effects of exposure to different microplastics concentrations $\left(0,10,10^{4}\right.$, and $10^{6}$ particles/L) on the parameters of cellular energy allocation (CEA) in the digestive gland of $M$. coruscus. (A) The available energy ( $\left.E_{a}\right)$, (B) the energy consumption ( $\left.E_{c}\right)$, (C) CEA. Different lowercase letters indicate that at the same sampling time point, there are significant differences between different microplastics concentration groups $(p<0.05)$, and no letters indicate that at each sampling time point, there are no significant differences between different microplastic concentration groups $(p>0.05)$.

energy reserves. A significant increase in ETS activity of the mussels exposed to high concentrations of microplastics indicates activation of mitochondrial metabolism and an increase in the cellular ATP demand. The data available to date show variable effects of microplastics on the respiration of bivalves. In oysters Ostrea edulis the respiration rate was not significantly affected by exposures to different types of microplastics for 60 days, despite some variability among different microplastics treatments (Green, 2016). No effects of microplastics exposures (100 or 1,000 particles/L) were reported for the mussels Choromytilus chorus (Opitz et al., 2021). This variability likely reflects differences in the exposure conditions including the differences in the concentrations and types of used microplastics. In our exposures, only high concentrations $\left(10^{4}\right.$ or $10^{6}$ particles/L) elicited the respiratory response whereas (the lowest test concentrations) had no effect. Elevated cellular oxygen consumption in the mussels exposed to high levels of microplastics indicates high basal maintenance costs, likely due to the costs of the stress protection and damage repair. High concentrations of microplastics can induce oxidative stress and inflammation in marine bivalves (Hu and Palić, 2020; Sendra et al., 2021) requiring expression of energetically costly protective mechanisms, such as antioxidants, molecular chaperones, protein quality control, and immune responses (Détrée and GallardoEscárate, 2017, 2018; Cole et al., 2020).

The decrease in energy reserves of $M$. coruscus exposed to high concentrations of microplastics $\left(10^{4}\right.$ or $10^{6}$ particles/L) indicates that the elevated energy demand is not compensated by an increase in energy uptake. This notion is supported by earlier reports that microplastics significantly suppress the filtration rate and energy assimilation efficiency of mussels (Gardon et al., 2018; Pedersen et al., 2020). Different energy reserves were engaged at different times of exposure to support energy demand of microplastics-exposed mussels. Carbohydrates (glycogen) reserves in the digestive gland were depleted already after 7 days of exposure to high concentration of microplastics, whereas the tissue levels of lipids and proteins decreased only after 14 days of exposure. The early depletion of glycogen is consistent with its role as a rapidly mobilizable metabolic fuel used to cover a rapid increase in energy demand in bivalves, for example during environmental stress or onset of gametogenesis (Smolders et al., 2004). Glycogen is also rapidly resynthesized after the microplastics exposure ceased in the mussels reaching the baseline levels after 7 days of recovery. In contrast, depletion of lipids and proteins occurs later during the microplastic exposure and takes longer to recover after the exposure ceases. A similar decrease in the levels of triglycerides, one of the main components of lipid storage, was found in the digestive glands of oyster Crassostrea gigas (Teng et al., 2021). These findings show an important role of lipids in supporting elevated metabolism during long-term exposures to microplastics.

Interestingly, the protein content of the digestive gland has shown a significant decline after 14 days of exposure to high concentrations of microplastics $\left(10^{4}\right.$ or $10^{6}$ particles/L) in $M$. coruscus. This finding was unexpected because protein breakdown is considered a last resort used only during prolonged starvation or periods of extreme energy demands (Albentosa et al., 2007; Haider et al., 2018). A decrease in the protein content in microplastics-exposed mussels might therefore indicate severe energy deficiency. Alternatively, lower protein content might 
indicated suppressed protein synthesis or elevated protein turnover in microplastics-exposed M. coruscus. Our previous research found that microplastics can reduce the activity of digestive proteases, thereby affecting the absorption of amino acids by mussels (Wang X. et al., 2020). Therefore, amino acid limitation might negatively affect the protein synthesis capacity of the mussels exposed to high concentrations of microplastics. This hypothesis requires further testing, but regardless of the underlying mechanism, protein loss in the mussels' tissues is expected to have negative effect on the metabolic performance and structural integrity of the cells that are critically dependent on the proteins. Overall, the total amount of energy $\left(E_{a}\right)$ was decreased in the mussels exposed to high concentrations of microplastics after 14 days reflecting lower content of all three major types of metabolic fuels. The CEA was also suppressed during the entire period of microplastics exposure demonstrating mismatch between the cellular energy demand and energy provision. An incomplete recovery of $\mathrm{E}_{\mathrm{a}}$ and CEA after 7 days indicate that high concentrations of microplastics have longterm negative effects of the energy budget of the mussels, and further research is needed to determine whether these effects are reversible.

Overall, our present study demonstrates the utility of the CEA approach to detect negative physiological effects of microplastics in marine animals and differentiate between the concentrations that might be relatively benign to the mussels (10 particles/L) and those that show strong negative effects $\left(10^{4}\right.$ or $10^{6}$ particles/L). However, high concentrations $\left(1.1 \times 10^{5}\right.$ particles/L) of microplastic uptaken showed no significant effects on the CEA of Mytilus edulis in polluted habitats (Van Cauwenberghe et al., 2015), which may be due to species specific response of mussels to microplastics. The CEA might be useful in environmental risk assessment of microplastics, since a decrease in CEA has

\section{REFERENCES}

Albentosa, M., Fernández-Reiriz, M. J., Labarta, U., and Pérez-Camacho, A. (2007). Response of two species of clams, Ruditapes decussatus and Venerupis pullastra, to starvation: physiological and biochemical parameters. Comp. Biochem. Physiol. B Biochem. 146, 241-249. doi: 10.1016/j.cbpb.2006.10.109

Andrady, A. L., and Neal, M. A. (2009). Applications and societal benefits of plastics. Philos. Trans. R. Soc. Lond. B Biol. Sci. 364, 1977-1984. doi: 10.1098/ rstb.2008.0304

Botterell, Z. L., Beaumont, N., Dorrington, T., Steinke, M., Thompson, R. C., and Lindeque, P. K. (2019). Bioavailability and effects of microplastics on marine zooplankton: A review. Environ. Pollut. 245, 98-110. doi: 10.1016/j.envpol. 2018.10.065

Bradford, M. (1976). A rapid and sensitive method for quantitation of microgram quantities of quantitation of microgram quantities of protein utilizing the principle of protein-dye binding. Anal. Biochem. 72, 248-254. doi: 10.1016/ 0003-2697(76)90527-3

Brandts, I., Teles, M., Gonçalves, A. P., Barreto, A., Franco-Martinez, L., Tvarijonaviciute, A., et al. (2018). Effects of nanoplastics on Mytilus galloprovincialis after individual and combined exposure with carbamazepine. Sci. Total Environ. 643, 775-784. doi: 10.1016/j.scitotenv.2018.06.257

Burns, E. E., and Boxall, A. B. A. (2018). Microplastics in the aquatic environment: Evidence for or against adverse impacts and major knowledge gaps. Environ. Toxicol. Chem. 37, 2776-2796. doi: 10.1002/etc.4268

Capolupo, M., Franzellitti, S., Valbonesi, P., Sanz Lanzas, C., and Fabbri, E. (2018). Uptake and transcriptional effects of polystyrene microplastics in larval stages immediate implications for growth, reproduction, immunity or stress response (Erk et al., 2011) and can thus help identifying habitats where mussels performance and sustainable growth would be negatively impacted by environmental stressors (Gomes et al., 2015; Wu et al., 2021) including microplastics pollution.

\section{DATA AVAILABILITY STATEMENT}

The original contributions presented in the study are included in the article/supplementary material, further inquiries can be directed to the corresponding author/s.

\section{AUTHOR CONTRIBUTIONS}

YS, XW, WH, and YW contributed to the conception and design of the study. YS, XW, MH, and XC performed the statistical analysis. YS, XW, XC, IS, SW, and MH wrote the first draft of the manuscript. WL and JF wrote sections of the manuscript. All authors contributed to the manuscript revision, read, and approved the submitted version.

\section{FUNDING}

We acknowledge grants from the National Natural Science Foundation of China (31872587 and 42076169), the Scientific Research Fund of the Second Institute of Oceanography (MNR, JG2109), the Zhejiang Provincial Natural Science Founds for Distinguished Young Scientists (LR21D060001), and the State Key Laboratory of Satellite Ocean Environment Dynamics (No. SOEDZZ2102).

of the Mediterranean mussel Mytilus galloprovincialis. Environ. Pollut. 241, 1038-1047. doi: 10.1016/j.envpol.2018.06.035

Cole, M., Liddle, C., Consolandi, G., Drago, C., Hird, C., Lindeque, P. K., et al. (2020). Microplastics, microfibres and nanoplastics cause variable sub-lethal responses in mussels (Mytilus spp.). Mar. Pollut. Bull. 160:111552. doi: 10.1016/ j.marpolbul.2020.111552

De Coen, W. M., and Janssen, C. (1997). The use of biomarkers in Daphnia magna toxicity testing. IV. Cellular energy allocation: a new methodology to assess the energy budget of toxicant-stressed Daphnia populations. J. Aquat. Ecosyst. Stress. Recovery 6, 43-55.

De Coen, W. M., and Janssen, C. R. (2003). The missing biomarker link: Relationships between effects on the cellular energy allocation biomarker of toxicant-stressed Daphnia magna and corresponding population characteristics. Environ. Toxicol. Chem. 22, 1632-1641. doi: 10.1897/1551-5028(2003)22<1632:tmblrb >2.0.co;2

De Sá, L. C., Oliveira, M., Ribeiro, F., Rocha, T. L., and Futter, M. N. (2018). Studies of the effects of microplastics on aquatic organisms: what do we know and where should we focus our efforts in the future? Sci. Total Environ. 645, 1029-1039. doi: 10.1016/j.scitotenv.2018.07.207

Détrée, C., and Gallardo-Escárate, C. (2017). Polyethylene microbeads induce transcriptional responses with tissue-dependentpatterns in the mussel Mytilus galloprovincialis. J. Molluscan Stud. 83, 220-225. doi: 10.1093/mollus/eyx005

Détrée, C., and Gallardo-Escárate, C. (2018). Single and repetitive microplastics exposures induce immune system modulation and homeostasis alteration in the edible mussel Mytilus galloprovincialis. Fish Shellfish Immunol. 83, 52-60. doi: 10.1016/j.fsi.2018.09.018 
Erk, M., Ivanković, D., and Strižak, Ž (2011). Cellular energy allocation in mussels (Mytilus galloprovincialis) from the stratified estuary as a physiological biomarker. Mar. Pollut. Bull. 62, 1124-1129. doi: 10.1016/j.marpolbul.2011.02. 056

Fanslow, D. L., Nalepa, T. F., and Johengen, T. H. (2001). Seasonal changes in the respiratory electron transport system (ETS) and respiration of the zebra mussel, Dreissena polymorpha in Saginaw Bay, Lake Huron. Hydrobiologia 448, 61-70.

Galloway, T. S., and Lewis, C. N. (2016). Marine microplastics spell big problems for future generations. Proc. Natl. Acad. Sci. 113, 2331-2333. doi: 10.1073/pnas. 1600715113

Gardon, T., Reisser, C., Soyez, C., Quillien, V., and Le Moullac, G. (2018). Microplastics affect energy balance and gametogenesis in the pearl oyster Pinctada margaritifera. Environ. Sci. Technol. 52, 5277-5286. doi: 10.1021/acs. est. 8 b00168

Giesy, J. P., and Graney, R. L. (1989). Recent developments in and intercomparisons of acute and chronic bioassays and bioindicators. Environmental Bioassay Techniques and their Application. Dordrecht: Springer, 21-60.

Gnaiger, E. (1983). Calculation of energetic and biochemical equivalents of respiratory oxygen consumption. Polarographic oxygen sensors. Berlin, Heidelberg: Springer, 337-345.

Gomes, S. I., Scott-Fordsmand, J. J., and Amorim, M. J. (2015). Cellular energy allocation to assess the impact of nanomaterials on soil invertebrates (Enchytraeids): the effect of $\mathrm{Cu}$ and Ag. Int. J. Environ. Res. Public Health. 12, 6858-6878. doi: 10.3390/ijerph120606858

Gosling, E. G. (1992). The mussel Mytilus: ecology, physiology, genetics and culture. Dev. Aquac. Fish Sci. 25:589.

Green, D. S. (2016). Effects of microplastics on European flat oysters, Ostrea edulis and their associated benthic communities. Environ. Pollut. 216, 95-103. doi: 10.1016/j.envpol.2016.05.043

Haider, F., Sokolov, E. P., and Sokolova, I. M. (2018). Effects of mechanical disturbance and salinity stress on bioenergetics and burrowing behavior of the soft-shell clam Mya arenaria. J. Exp. Biol. 221:jeb172643.

Hamm, T., and Lenz, M. (2021). Negative impacts of realistic doses of spherical and irregular microplastics emerged late during a 42 weeks-long exposure experiment with blue mussels. Sci. Total Environ. 778:146088. doi: 10.1016/j. scitotenv.2021.146088

$\mathrm{Hu}$, M., and Palić, D. (2020). Micro- and nano-plastics activation of oxidative and inflammatory adverse outcome pathways. Redox Biol. 37:101620. doi: 10.1016/ j.redox.2020.101620

Ivanina, A. V., Kurochkin, I. O., Leamy, L., and Sokolova, I. M. (2012). Effects of temperature and cadmium exposure on the mitochondria of oysters (Crassostrea virginica) exposed to hypoxia and subsequent reoxygenation. J. Exp. Biol. 215, 3142-3154.

Khan, M. B., and Prezant, R. S. (2018). Microplastic abundances in a mussel bed and ingestion by the ribbed marsh mussel Geukensia demissa. Mar. Pollut. Bull. 130, 67-75. doi: 10.1016/j.marpolbul.2018.03.012

Larue, C., Sarret, G., Castillo-Michel, H., and Pradas del Real, A. E. (2021). A critical review on the impacts of nanoplastics and microplastics on aquatic and terrestrial photosynthetic organisms. Small 17:2005834. doi: 10.1002/smll. 202005834

Li, J., Lusher, A. L., Rotchell, J. M., Deudero, S., Turra, A., Bråte, I. L. N., et al. (2019). Using mussel as a global bioindicator of coastal microplastic pollution. Environ. Pollut. 244, 522-533. doi: 10.1016/j.envpol.2018.10.032

Li, Q., Feng, Z., Zhang, T., Ma, C., and Shi, H. (2020). Microplastics in the commercial seaweed nori. J. Hazard. Mater. 388:122060. doi: 10.1016/j.jhazmat. 2020.122060

Ma, J., Niu, X., Zhang, D., Lu, L., Ye, X., Deng, W., et al. (2020). High levels of microplastic pollution in aquaculture water of fish ponds in the Pearl River Estuary of Guangzhou, China. Sci. Total Environ. 744:140679. doi: 10.1016/j. scitotenv.2020.140679

MacArthur, E. (2017). Beyond plastic waste. Science 358:843. doi: 10.1126/science. aao6749

Magni, S., Gagne, F., Andre, C., Della Torre, C., Auclair, J., Hanana, H., et al. (2018). Evaluation of uptake and chronic toxicity of virgin polystyrene microbeads in freshwater zebra mussel Dreissena polymorpha (Mollusca: Bivalvia). Sci. Total Environ. 631-632, 778-788. doi: 10.1016/j.scitotenv.2018.03. 075
Müller, C. (2021). Not as bad as it seems? A literature review on the case of microplastic uptake in fish. Front. Mar. Sci. 8:672768. doi: 10.3389/fmars.2021. 672768

Noor, M. N., Wu, F., Sokolov, E. P., Falfushynska, H., Timm, S., Haider, F., et al. (2021). Salinity-dependent effects of $\mathrm{ZnO}$ nanoparticles on bioenergetics and intermediate metabolite homeostasis in a euryhaline marine bivalve, Mytilus edulis. Sci. Total Environ. 774:145195. doi: 10.1016/j.scitotenv.2021.145195

Opitz, T., Benítez, S., Fernández, C., Osores, S., Navarro, J. M., Rodríguez-Romero, A., et al. (2021). Minimal impact at current environmental concentrations of microplastics on energy balance and physiological rates of the giant mussel Choromytilus chorus. Mar. Pollut. Bull. 162:111834. doi: 10.1016/j.marpolbul. 2020.111834

Pedersen, A. F., Gopalakrishnan, K., Boegehold, A. G., Peraino, N. J., Westrick, J. A., and Kashian, D. R. (2020). Microplastic ingestion by quagga mussels, Dreissena bugensis, and its effects on physiological processes. Environ. Pollut. 260:113964. doi: 10.1016/j.envpol.2020.113964

Pinheiro, L. M., Ivar do Sul, J. A., and Costa, M. F. (2020). Uptake and ingestion are the main pathways for microplastics to enter marine benthos: A review. Food Webs 24:e00150. doi: 10.1016/j.fooweb.2020.e00150

Rochman, C. M., Brookson, C., Bikker, J., Djuric, N., Earn, A., Bucci, K., et al. (2019). Rethinking microplastics as a diverse contaminant suite. Environ. Toxicol. Chem. 38, 703-711. doi: 10.1002/etc.4371

Sendra, M., Sparaventi, E., Novoa, B., and Figueras, A. (2021). An overview of the internalization and effects of microplastics and nanoplastics as pollutants of emerging concern in bivalves. Sci. Total Environ. 753:142024. doi: 10.1016/j. scitotenv.2020.142024

Smolders, R., Bervoets, L., De Coen, W., and Blust, R. (2004). Cellular energy allocation in zebra mussels exposed along a pollution gradient: linking cellular effects to higher levels of biological organization. Environ. Pollut. 129, 99-112. doi: 10.1016/j.envpol.2003.09.027

Smolders, R., De Boeck, G., and Blust, R. (2003). Changes in cellular energy budget as a measure of whole effluent toxicity in zebrafish (Danio rerio). Environ. Toxicol. Chem. 22, 890-899. doi: 10.1002/etc.5620220429

Sokolova, I. (2021). Bioenergetics in environmental adaptation and stress tolerance of aquatic ectotherms: linking physiology and ecology in a multi-stressor landscape. J. Exp. Biol. 224:jeb236802.

Sokolova, I. M., Sukhotin, A. A., and Lannig, G. (2012). Stress effects on metabolism and energy budgets in mollusks. Oxidative stress in aquatic ecosystems. Hoboken, NJ: Wiley-Blackwell, 263-280.

Teng, J., Wang, Q., Ran, W., Wu, D., Liu, Y., Sun, S., et al. (2019). Microplastic in cultured oysters from different coastal areas of China. Sci. Total Environ. 653, 1282-1292. doi: 10.1016/j.scitotenv.2018.11.057

Teng, J., Zhao, J., Zhu, X., Shan, E., Zhang, C., Zhang, W., et al. (2021). Toxic effects of exposure to microplastics with environmentally relevant shapes and concentrations: Accumulation, energy metabolism and tissue damage in oyster Crassostrea gigas. Environ. Pollut. 269:116169. doi: 10.1016/j.envpol.2020. 116169

Van Cauwenberghe, L., Claessens, M., Vandegehuchte, M. B., and Janssen, C. R. (2015). Microplastics are taken up by mussels (Mytilus edulis) and lugworms (Arenicola marina) living in natural habitats. Environ. Pollut. 199, 10-17. doi: 10.1016/j.envpol.2015.01.008

Van Dievel, M., Janssens, L., and Stoks, R. (2019). Additive bioenergetic responses to a pesticide and predation risk in an aquatic insect. Aquat. Toxicol. 212, 205-213. doi: 10.1016/j.aquatox.2019.05.010

Van Handel, E. (1985). Rapid determination of total lipids in mosquitoes. J. Am. Mosq. Control. Assoc. 1, 302-304.

Verslycke, T., Ghekiere, A., and Janssen, C. R. (2004a). Seasonal and spatial patterns in cellular energy allocation in the estuarine mysid Neomysis integer (Crustacea: Mysidacea) of the Scheldt estuary (The Netherlands). J. Exp. Mar. Bio. Ecol. 306, 245-267. doi: 10.1016/j.jembe.2004.01.014

Verslycke, T., Roast, S. D., Widdows, J., Jones, M. B., and Janssen, C. R. (2004b) Cellular energy allocation and scope for growth in the estuarine mysid Neomysis integer (Crustacea: Mysidacea) following chlorpyrifos exposure: a method comparison. J. Exp. Mar. Bio. Ecol. 306, 1-16. doi: 10.1016/j.jembe.2003.12.022

Verslycke, T., Vercauteren, J., Devos, C., Moens, L., Sandra, P., and Janssen, C. R. (2003). Cellular energy allocation in the estuarine mysid shrimp Neomysis integer (Crustacea: Mysidacea) following tributyltin exposure. J. Exp. Mar. Bio. Ecol. 288, 169-179. 
Wang, C., Zhao, J., and Xing, B. (2020). Environmental source, fate, and toxicity of microplastics. J. Hazard. Mater. 407:124357. doi: 10.1016/j.jhazmat.2020. 124357

Wang, X., Huang, W., Wei, S., Shang, Y., Gu, H., Wu, F., et al. (2020). Microplastics impair digestive performance but show little effects on antioxidant activity in mussels under low pH conditions. Environ. Pollut. 258:113691. doi: 10.1016/j. envpol.2019.113691

Watts, A. J., Urbina, M. A., Corr, S., Lewis, C., and Galloway, T. S. (2015). Ingestion of plastic microfibers by the crab Carcinus maenas and its effect on food consumption and energy balance. Environ. Sci. Technol. 49, 14597-14604. doi: 10.1021/acs.est.5b04026

Weis, J., Andrews, C. J., Dyksen, J. E., Ferrara, R. A., Gannon, J. T., Laumbach, R. J., et al. (2015). Human health impact of microplastics and nanoplastics. New Jersy: NJDEP-Science Advisory Board.

Widdows, J., and Johnson, D. (1988). Physiological energetics of Mytilus edulis: scope for growth. Mar. Ecol. Prog. Ser. 46, 113-121. doi: 10.3354/meps046113

Wright, S. L., Rowe, D., Thompson, R. C., and Galloway, T. S. (2013a). Microplastic ingestion decreases energy reserves in marine worms. Curr. Biol. 23, R1031R1033.

Wright, S. L., Thompson, R. C., and Galloway, T. S. (2013b). The physical impacts of microplastics on marine organisms: A review. Environ. Pollut. 178, 483-492. doi: 10.1016/j.envpol.2013.02.031

Wu, F., Sokolov, E. P., Dellwig, O., and Sokolova, I. M. (2021). Season-dependent effects of $\mathrm{ZnO}$ nanoparticles and elevated temperature on bioenergetics of the blue mussel Mytilus edulis. Chemosphere 263:127780. doi: 10.1016/j. chemosphere.2020.127780

Xu, S., Ma, J., Ji, R., Pan, K., and Miao, A. J. (2020). Microplastics in aquatic environments: occurrence, accumulation, and biological effects. Sci. Total Environ. 703:134699. doi: 10.1016/j.scitotenv.2019.134699

Yin, L., Chen, B., Xia, B., Shi, X., and Qu, K. (2018). Polystyrene microplastics alter the behavior, energy reserve and nutritional composition of marine jacopever
(Sebastes schlegelii). J. Hazard. Mater. 360, 97-105. doi: 10.1016/j.jhazmat.2018. 07.110

Yu, P., Liu, Z., Wu, D., Chen, M., Lv, W., and Zhao, Y. (2018). Accumulation of polystyrene microplastics in juvenile Eriocheir sinensis and oxidative stress effects in the liver. Aquat. Toxicol. 200, 28-36. doi: 10.1016/j.aquatox.2018.04. 015

Zhao, J., Ran, W., Teng, J., Liu, Y., Liu, H., Yin, X., et al. (2018). Microplastic pollution in sediments from the Bohai Sea and the Yellow Sea, China. Sci. Total Environ. 640, 637-645. doi: 10.1016/j.scitotenv.2018.05.346

Zhao, S., Zhu, L., Wang, T., and Li, D. (2014). Suspended microplastics in the surface water of the yangtze estuary system, China: First observations on occurrence, distribution. Mar. Pollut. Bull. 86, 562-568. doi: 10.1016/j. marpolbul.2014.06.032

Conflict of Interest: The authors declare that the research was conducted in the absence of any commercial or financial relationships that could be construed as a potential conflict of interest.

Publisher's Note: All claims expressed in this article are solely those of the authors and do not necessarily represent those of their affiliated organizations, or those of the publisher, the editors and the reviewers. Any product that may be evaluated in this article, or claim that may be made by its manufacturer, is not guaranteed or endorsed by the publisher.

Copyright (c) 2021 Shang, Wang, Chang, Sokolova, Wei, Liu, Fang, Hu, Huang and Wang. This is an open-access article distributed under the terms of the Creative Commons Attribution License (CC BY). The use, distribution or reproduction in other forums is permitted, provided the original author(s) and the copyright owner(s) are credited and that the original publication in this journal is cited, in accordance with accepted academic practice. No use, distribution or reproduction is permitted which does not comply with these terms. 